\title{
Regional Tourism Economic Impact Evaluation Based on Dynamic Input-Output Model
}

\author{
Ruili Cao \\ Academic Affairs Office, Henan Institute of Technology, Xinxiang, Henan 453003, China \\ Correspondence should be addressed to Ruili Cao; crl@hait.edu.cn
}

Received 6 December 2021; Revised 27 December 2021; Accepted 30 December 2021; Published 1 February 2022

Academic Editor: Miaochao Chen

Copyright ( 92022 Ruili Cao. This is an open access article distributed under the Creative Commons Attribution License, which permits unrestricted use, distribution, and reproduction in any medium, provided the original work is properly cited.

\begin{abstract}
The level of inbound tourism development is an important criterion to measure the internationalization of tourism, which is an important factor representing the tourism economy. Taking Anhui province as the research object, the inbound tourism development efficiency of 16 cities in Anhui province from 2011 to 2019 is analyzed with the help of the DEA model and Malmquist index, and the key factors affecting the inbound tourism development efficiency are analyzed with the OLS model. It is found that (1) the overall development of inbound tourism in Anhui province is in a high state, but there are still phenomena such as waste of resources, overexploitation, and unreasonable industrial investment, which lead to the unbalanced and insufficient development of regional inbound tourism. (2) Inbound tourism efficiency in Anhui province is influenced by the level of economic development, tourism resource endowment, accessibility, and the scale of human resources, suggesting that inbound tourism is essentially natural resource, infrastructure, and service facility driven. The study is important to clarify the path of improving the efficiency of inbound tourism, promote the development of high-quality inbound tourism, and thus achieve high-quality transformation of tourism.
\end{abstract}

\section{Introduction}

Since the reform and opening up in 1978, China's tourism industry has achieved leaps and bounds and has made remarkable achievements. Tourism has become a pillar industry of the national economy, accounting for $11.05 \%$ of the total GDP in 2019. Inbound tourism is an important part of tourism and an important driver of trade in services, with an important role in driving consumption, and is "an export that does not have to go out of the country" [1], and its development level is often an important symbol to measure the internationalization level of a country or region's tourism industry and the maturity of the industry [2]. The economic effect of inbound tourism is an important part of the economic effect of tourism and is an integral part of measuring the economic impact of tourism that cannot be ignored. Therefore, the development of inbound tourism is the most effective way to transform, upgrade, and improve the quality and efficiency of tourism. China's inbound tourism has also made impressive achievements along with the relaunch of China's tourism industry, with the number of inbound tourists received growing from 1.809 million in
1978 to 141 million in 2019, achieving international tourism foreign exchange earnings of $\$ 131.254$ billion, and inbound tourism has become an important channel for the country to generate foreign exchange. However, the booming development of inbound tourism has triggered local governments to expect to promote the longitudinal development of the tourism industry through large-scale investment in the tourism industry and various subsectors to drive GDP growth and economic structure transformation but ignore the problem of rational allocation of tourism industry inputs and outputs, which leads to redundancy and overconsumption of resources within the industry [3]. The efficiency of the tourism industry is an important indicator for evaluating the rationality of regional tourism industry inputs and outputs, specifically referring to the nature of maximizing output per unit of factor input in a specific time frame under established economic and technical conditions, and prompting tourism stakeholders to maximize their total surplus [4]. Therefore, in the context of inbound tourism as an important way for the government to generate foreign exchange, it is of great practical significance to pay attention to the issue of inbound tourism efficiency in order to achieve 
an efficient allocation of regional tourism factors, improve the quality of the industry, and transform the growth model of the tourism economy.

The importance of tourism efficiency issues has sparked extensive attention from scholars. Morey and Dittman [5] were the first to focus on the efficiency of private hotel chains in the U.S. and found that the private hotel chain business model was more efficient. Subsequently, scholars provided an in-depth discussion on hotel efficiency measurement $[6,7]$. With the popularity of DEA methods, scholars have further discussed the efficiency of different types of objects such as tourist destinations [8-10], scenic spots [11, 12], travel agencies $[13,14]$, and tourist transportation $[15,16]$, providing an extensive literature based on the legitimacy of DEA applications in tourism research. Focusing on the field of inbound tourism, Tang [17] explored the uneven growth of inbound tourism in China and its impact on the spatial structure of the regional economy. Other scholars have discussed the spatial and temporal evolution patterns and characteristics of inbound tourism flows $[18,19]$. However, these studies focus on the spatiotemporal effects of inbound tourism and lack attention to the regional economic impacts of inbound tourism, not to mention the lack of case studies of specialty regions. Anhui province is the "starting point" of China's tourism relaunch, and Mount Huangshan, a World's Cultural and Natural Heritage site, is the key to its entry into the international tourism market. However, despite the increase in the number of inbound tourism arrivals and foreign exchange earnings over the past 30 years, Anhui province received 6.558 million inbound tourists and US $\$ 3.39$ billion in foreign exchange earnings in 2019 , but the overall ranking of inbound tourism has always lingered in front of the top 10 thresholds in China, highlighting the disconnection between resource endowment and market demand. These figures show that Anhui province is far behind Guangzhou, Shanghai, and Beijing in terms of inbound tourism efficiency in the long run, despite its firstmover advantage in China's tourism development process. So, why Anhui province cannot open up the international tourism market completely? This study will take Anhui province as an example on the basis of previous research results, use inbound tourism statistics from 2011 to 2019, dynamically capture the spatial and temporal characteristics and changes in inbound tourism development efficiency in Anhui province based on the DEA-Malmquist model, and further analyze the main influencing factors of inbound tourism development efficiency in the region using OLS model, in order to clarify the path of regional inbound tourism efficiency improvement and provide a reference basis for promoting the high-quality development of inbound tourism and thus realizing the high-quality transformation of tourism.

\section{Research Method}

2.1. DEA Model. Data envelopment analysis (DEA) is a nonparametric estimation method most commonly used in efficiency evaluation (Figure 1). The advantages of this method are that it does not consider specific production functions, does not require pre-estimated parameters and weights, can handle different types of data, and has absolute advantages in dealing with multiple input and output problems [20]. The basic idea of the three-stage DEA method is that the input-output efficiency of a decision unit is influenced by three major factors, such as external environment, internal management, and random disturbance. Therefore, the efficiency evaluation of a decision unit needs to separate the role of the external environment and random error so that the efficiency value of the decision unit can more objectively and truly reflect the internal management level [15]. This process not only avoids the problem of the inability to separate the efficiency-influencing factors in the first-stage DEA but also solves the shortcomings of the second-stage DEA method, which is influenced by the form of the function of the influencing factors and the inability to separate the random errors, and greatly improves the objectivity and accuracy of the efficiency evaluation. Therefore, it is widely used in tourism industry research.

The traditional DEA model is a static analysis of efficiency, and the most common ones are the CCR model and BCC model, while the Malmquist index can measure the dynamic efficiency of the tourism industry. Therefore, DEA and Malmquist index are combined to evaluate the efficiency of inbound tourism development. The DEA model is as follows $[21,22]$ :

$$
\begin{aligned}
& \min \left(\theta-\varepsilon\left(e_{1}^{T} s^{-}+e_{2}^{T} s^{+}\right)\right), \\
& \text {s.t. } \sum_{j=1}^{k} X_{m l} \lambda_{m}+s^{-}=\theta x_{1}^{n} ; l=1, \ldots, L, \\
& \quad \sum_{j=1}^{k} y_{m k} \lambda_{m}+s^{+}=y_{1}^{m} ; k=1, \ldots, k, \\
& \quad \lambda m \geq 0 ; m=1,2, \ldots, M .
\end{aligned}
$$

$M$ denotes the number of cities; $L$ denotes the input index; $K$ denotes the output index; let $x_{m l}>0, x_{m l}$ means the first resource input of the $m$ th city; and $y_{m k}$ means the $k$ output of the $m$ city. The final measurement result of CRS is the comprehensive efficiency, which refers to the comprehensive measurement and evaluation of the resource allocation ability and resource-use efficiency of the decision unit. The overall efficiency can be further decomposed into pure technical efficiency (VRS) and scale efficiency (SCAL). Pure technical efficiency is the production efficiency influenced by management and technology, while scale efficiency is the production efficiency influenced by the size of the enterprise.

2.2. Malmquist Model. $\left(x^{t}, y^{t}\right)$ denotes the input and output quantities in period $t, D_{c}^{t}\left(x^{t}, y^{t}\right)$ denotes the output distance function under the technical conditions in period $t, M^{t}$ denotes the value of change in efficiency from period $t$ to period $t+1$ under the technical conditions in period $t$, $\left(x^{t+1}, y^{t+1}\right)$ denotes the input and output quantities in period $t+1, D_{c}^{t+1}\left(x^{t+1}, y^{t+1}\right)$ denotes the output distance function under the technical conditions in period $t+1$, and $M^{t+1}$ denotes the value of change in efficiency from period $t$ 


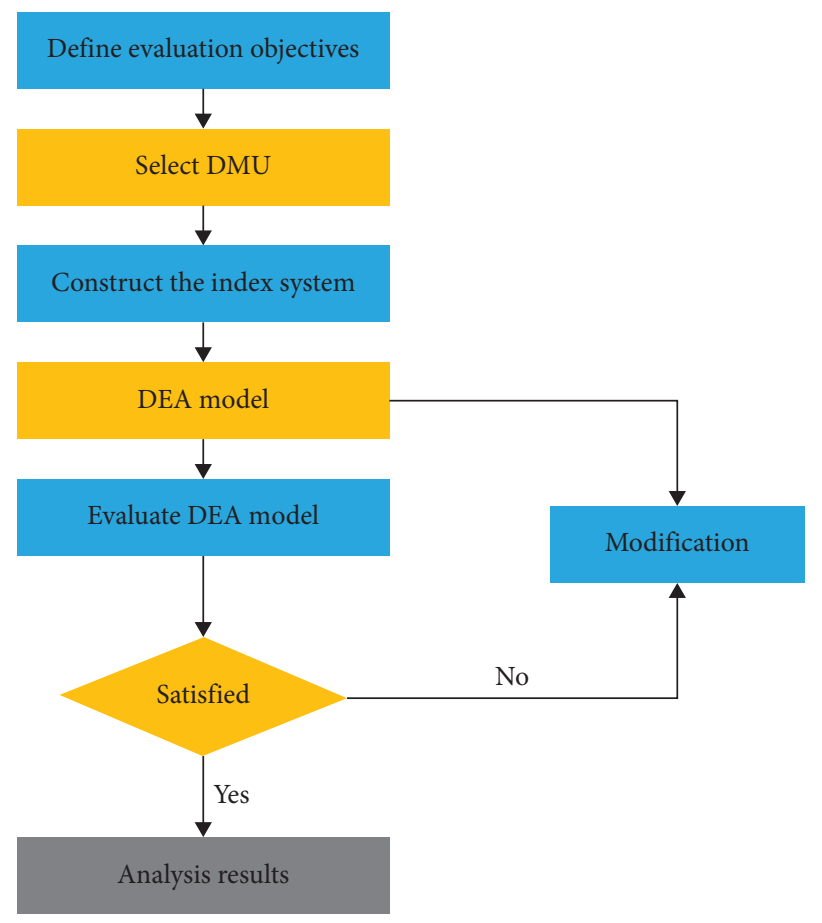

FiguRE 1: DEA process.

to period $t+1$ under the technical conditions in period $t+1$. The Malmquist index formula is as follows [23]:

$$
\begin{aligned}
M_{c}^{t} & =\frac{D_{c}^{t}\left(x^{t+1}+y^{t+1}\right)}{D_{c}^{t}\left(x^{t}+y^{t}\right)}, \\
M_{c}^{t+1} & =\frac{D_{c}^{t+1}\left(x^{t+1}+y^{t+1}\right)}{D_{c}^{t+1}\left(x^{t}+y^{t}\right)}, \\
M^{t+1}\left(x^{t+1}, y^{t+1}, x^{t}, y^{t}\right) & =\left(M^{t} \times M^{t+1}\right)^{(1 / 2)}, \\
\left(M^{t} \times M^{t+1}\right)^{(1 / 2)} & =\left[\frac{D_{c}^{t}\left(x^{t+1}+y^{t+1}\right)}{D_{c}^{t}\left(x^{t}+y^{t}\right)} \times \frac{D_{c}^{t+1}\left(x^{t+1}+y^{t+1}\right)}{D_{c}^{t+1}\left(x^{t}+y^{t}\right)}\right]^{(1 / 2)}, \\
\operatorname{TFP} & =\left[\frac{D_{c}^{t}\left(x^{t+1}+y^{t+1}\right)}{D_{c}^{t}\left(x^{t}+y^{t}\right)} \times \frac{D_{c}^{t+1}\left(x^{t+1}+y^{t+1}\right)}{D_{c}^{t+1}\left(x^{t}+y^{t}\right)}\right]^{(1 / 2)} .
\end{aligned}
$$

When TFP $>1$, it indicates an upward trend; when $\mathrm{TFP}=1$, it indicates no change; and when $\mathrm{TFP}<1$, it indicates a downward trend. Assuming constant returns to scale, TFP can be further decomposed into technical efficiency change (EFFCH) and technical progress change (TECH). Assuming variable returns to scale, EFFCH can be decomposed again into pure technical efficiency change $(\mathrm{PECH})$ and scale efficiency change (SECH). Therefore, the TFP is calculated as follows:

$$
M^{t+1}\left(x^{t+1}, y^{t+1}, x^{t}, y^{t}\right)=\mathrm{PECH} \times \mathrm{SECH} \times \mathrm{TECH},
$$$$
\mathrm{TFP}=\mathrm{EFFCH} \times \mathrm{TECH}=\mathrm{PECH} \times \mathrm{SECH} \times \mathrm{TECH} .
$$

2.3. OLS Model. We use an OLS model to regress the factors and magnitude of the impact of inbound tourism development efficiency in the following basic form:

$$
\begin{aligned}
y= & \beta_{0}+\beta_{1} \text { eco }_{i t}+\beta_{2} \operatorname{str}_{i t}+\beta_{3} \text { gov }_{i t}+\beta_{4} \operatorname{tre}_{i t} \\
& +\beta_{5} \operatorname{tra}_{i t}+\beta_{6} \mathrm{hrs}_{i t}+\beta_{7} \text { tei }_{i t}+\varepsilon,
\end{aligned}
$$

where $i$ represents the cross-sectional unit, i.e., the 17 city units of Anhui province; $t$ represents the time series, the period of investigation is 2011-2019; $\beta_{0}$ represents the constant; $\beta_{1}, \beta_{2}, \ldots, \beta_{7}$ represents the regression parameters; $\varepsilon$ represents the random error; $y$ is the overall efficiency of inbound tourism development; eco represents the economic development level; str represents the industrial structure; gov represents the degree of government intervention in tourism economy; tre represents tourism resource endowment; tra represents the transportation convenience; hrs represents the scale of human resources; and tei represents the technological innovation.

\subsection{Index System Construction and Data Sources}

2.4.1. Inbound Tourism Development Efficiency Evaluation Index System. Based on the principles of constructing indicator system such as scientificity, accessibility, and operability of data, combined with the requirements of DEA-Malmquist measurement involving multiple inputs and desired and nondesired outputs, alternative indicators are selected to construct the input-output indicator system of total factor productivity of inbound tourism in Anhui province (Figure 2). 


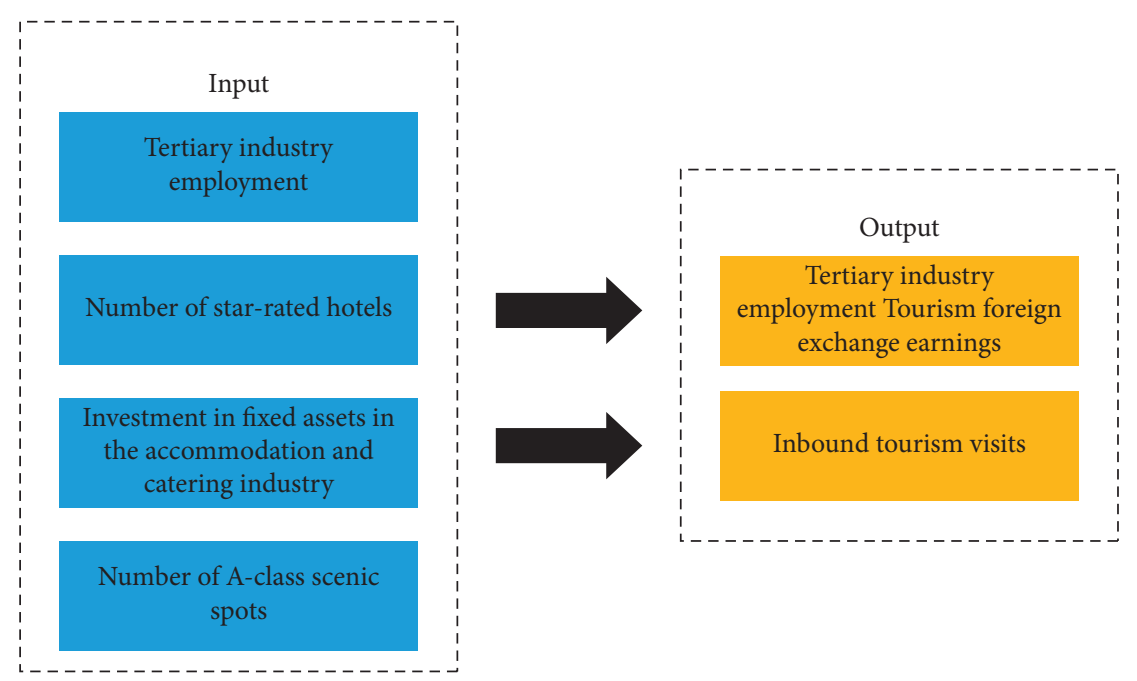

FIgURE 2: Input-output indicators.

Output indicators are selected based on two perspectives: one is the number of inbound tourism arrivals, reflecting the scale of the received passenger flow; the other is the foreign exchange earnings of inbound tourism, reflecting the comprehensive benefits of inbound tourism development. For input indicators, labor, capital, and land are the most basic factors of production in the efficiency calculation, but tourism development is less influenced by land and is generally not used as an input variable. In this study, the number of employments in tertiary industry and the amount of fixed asset investment in accommodation and catering industry are chosen to refer to labor and capital factors, respectively. In addition, the number of star-rated hotels and the number of A-class scenic spots represent the level of tourism infrastructure and service facilities in the destination. Table 1 presents the descriptive statistics of each type of indicator.

2.4.2. Influencing Factor Selection. Indicators were selected with reference to Yang et al. [24] based on a comprehensive selection of influencing factor indicators for both the external business environment and internal resource factors of inbound tourism development. Combining the availability of data and circumventing the multiple covariances of data, the influence of factors such as the degree of government intervention in the tourism economy, the level of economic development, accessibility, industrial structure, the scale of human resources, and technological innovation on the efficiency of inbound tourism development is theoretically explored. Economic development level: the level of economic development directly affects the amount of input factors for tourism, and economically developed regions have a larger scale of resource and technology investment and stronger resource utilization capacity, which is conducive to enhancing tourism development efficiency, expressed in terms of GDP per capita. Industrial structure: the optimization and upgrading of the industrial structure can improve the production efficiency of the regional tourism industry, and the proportion of comprehensive income from inbound tourism to the output value of the tertiary industry is used to reflect the rationality of the industrial structure. The degree of government intervention in the tourism economy: inbound tourism is an important channel to create foreign exchange earnings, and the government plays an important role in the growth of inbound tourism. Government actions directly act on tourism industry agglomeration and integration, which in turn affects the efficiency of tourism development. Since it is impossible to accurately measure the magnitude of government intervention in the tourism economy, the ratio of local fiscal expenditure to GDP is used as a proxy. Tourism resource endowment: tourism resources are the basis of tourism industry development and directly affect the attractiveness of tourism destinations, calculated by the number of red tourism scenic spots of $3 \mathrm{~A}$ and above. Traffic accessibility: traffic is a prerequisite for tourism development and can influence the decision of tourists. The accessibility of tourist attractions directly affects the tourist flow and the spatial spillover effect of the regional tourism economy, calculated in terms of road mileage. The scale of human resources: tourism is a labor-intensive industry, human capital promotes regional tourism economic efficiency, with the upgrading of the tourism industry structure, tourism industry demand for advanced and specialized talents increases, the scale of talent directly affects the improvement of tourism development efficiency, due to the lack of data on the number of students in tourism colleges, so the number of students with secondary vocational education and above is used instead. Technological innovation: the improvement of technology level in the tourism industry can influence tourism demand and tourism input, thus affecting the improvement of regional tourism development efficiency, replaced by the ratio of science and technology expenditure to local financial expenditure.

2.4.3. Data Source. The data in this study are all from the official data, including the Statistical Yearbook of Anhui Province, the Statistical Bulletin of National Economic and Social Development of Anhui Municipalities, and the official website of Anhui Culture and Tourism Bureau. 
TABLE 1: Input-output indicators of inbound tourism development efficiency.

\begin{tabular}{|c|c|c|c|c|c|}
\hline $\begin{array}{l}\text { Indicator } \\
\text { type }\end{array}$ & Index (unit) & Max & Min & Mean & $\mathrm{SD}$ \\
\hline Input & Tertiary industry employment (thousands) & 282.90 & 19.70 & 99.53 & 110.19 \\
\hline Input & Number of star-rated hotels (pcs) & 82.00 & 3.00 & 24.45 & 33.36 \\
\hline Input & $\begin{array}{c}\text { Investment in fixed assets in the accommodation and catering industry } \\
\text { (thousands) }\end{array}$ & 1802320.20 & 3243.77 & 168306.91 & 811988.05 \\
\hline Input & Number of A-class scenic spots (pcs) & 73.00 & 4.00 & 32.92 & 28.29 \\
\hline Output & Tourism foreign exchange earnings (thousands) & 497770 & 0.12 & 16849.84 & 100895.35 \\
\hline Output & Inbound tourist visits (thousands) & 286.94 & 1.20 & 28.21 & 128.81 \\
\hline
\end{tabular}

TABLE 2: Results of overall efficiency on inbound tourism.

\begin{tabular}{lccccccccc}
\hline & 2011 & 2012 & 2013 & 2014 & 2015 & 2016 & 2017 & 2018 & 2019 \\
\hline Hefei & 0.50 & 0.60 & 0.80 & 0.90 & 1.00 & 0.98 & 1.00 & 0.78 & 1.00 \\
Huaibei & 0.05 & 0.51 & 0.36 & 0.51 & 0.63 & 0.53 & 0.12 & 0.45 & 0.38 \\
Bozhou & 1.00 & 0.33 & 0.21 & 0.55 & 1.00 & 0.66 & 0.14 & 1.00 \\
Suzhou & 0.10 & 0.40 & 0.37 & 0.63 & 0.98 & 0.57 & 0.26 & 0.38 & 0.41 \\
Bengbu & 0.40 & 0.73 & 0.24 & 0.50 & 0.85 & 0.78 & 0.18 & 0.96 & 0.17 \\
Fuyang & 0.85 & 0.63 & 0.85 & 0.80 & 1.00 & 1.00 & 0.72 & 0.73 \\
Huainan & 0.46 & 0.46 & 0.37 & 0.67 & 0.94 & 1.00 & 0.08 & 0.59 \\
Chuzhou & 0.54 & 0.38 & 0.26 & 0.34 & 1.00 & 0.50 & 0.35 & 0.90 \\
Luan & 0.65 & 0.62 & 0.55 & 0.82 & 0.49 & 0.76 & 0.17 & 1.00 \\
Maanshan & 0.39 & 1.00 & 1.00 & 0.91 & 0.64 & 1.00 & 0.15 & 0.16 \\
Wuhu & 0.19 & 0.62 & 0.47 & 0.94 & 0.51 & 0.89 & 0.85 & 1.00 \\
Xuancheng & 0.20 & 0.25 & 0.19 & 0.39 & 0.45 & 0.46 & 0.15 & 0.18 \\
Tongling & 0.05 & 0.15 & 0.18 & 0.48 & 0.98 & 0.24 & 0.10 & 0.10 \\
Chizhou & 0.56 & 1.00 & 1.00 & 1.00 & 1.00 & 1.00 & 1.00 & 1.00 \\
Anqing & 0.10 & 0.71 & 0.50 & 1.00 & 0.56 & 0.99 & 0.59 & 0.19 \\
Huangshan & 1.00 & 1.00 & 1.00 & 1.00 & 1.00 & 1.00 & 1.00 & 1.00 \\
Mean & 0.151 & 0.58 & 0.56 & 0.71 & 0.81 & 0.77 & 0.34 & 0.14 \\
\hline
\end{tabular}

\section{Results and Discussion}

3.1. Overall Efficiency. Overall efficiency is a comprehensive evaluation of resource-use and tourism input-output efficiency. In this study, when the overall efficiency is equal to 1 , it indicates that the tourism resources of the city are effectively utilized and there is no waste of resources. When the overall efficiency is less than 1, it indicates that the tourism resources of the city are not fully utilized, and there is the phenomenon of resource waste or unreasonable input. Table 2 shows the inbound overall efficiency of each city in Anhui province from 2011 to 2019.

In particular, the inbound tourism overall efficiency of Anhui province greatly fluctuates from 2011 to 2019, showing a steady increase until 2015, but a sharp fluctuation after 2016, even only 0.34 in 2017, and back to 0.59 in 2019 . Among them, the overall inbound tourism effect of Hefei and Fuyang is in a steady increase, with high efficiency of tourism resource utilization, with reasonable tourism resource input. The overall efficiency of inbound tourism in Wuhu also shows a steady increase and reaches the optimum in 2018. The cities of Bozhou, Suzhou, and Bengbu have also been on a steady rise in overall efficiency, although they have not reached the optimal state. Chuzhou, Lu'an, and Maanshan all had only one year of inbound integrated efficiency value to the optimal state during the nine years, and the rest of the eight years have been in a lower state; Huabei,
Suizhou, Bengbu, Xuancheng, and Tongling have been in the lowest state of inbound integrated efficiency during the nine years, and no year is optimal, indicating that there are great differences in inbound tourism among the cities (Figures 3-5).

3.2. Technical Efficiency. Technical efficiency indicates the degree of technical management of the combination of tourism resource input elements in tourism development without considering the scale element, with higher technical efficiency indicating a higher level of management. Technical efficiency reflects the use of a city's technical level of existing tourism resources and the development and utilization of productivity production factors and can directly reflect a city's use of resources for the use of inputs, and there is a surplus of resource input, which causes waste of resources. According to the difference between the regional input and output, the pure technical efficiency can be accurately judged, and when the difference value is larger, it means that the pure technical efficiency is lower. When the value of pure technical efficiency is 1 , it means that the use of technical elements of tourism resources is the most reasonable, and when the value of pure technical efficiency is lower than 1 , it means that there are unreasonable phenomena in the use and development of tourism resources, and there is a redundancy of resources, and when the value is closer to 1 , it 


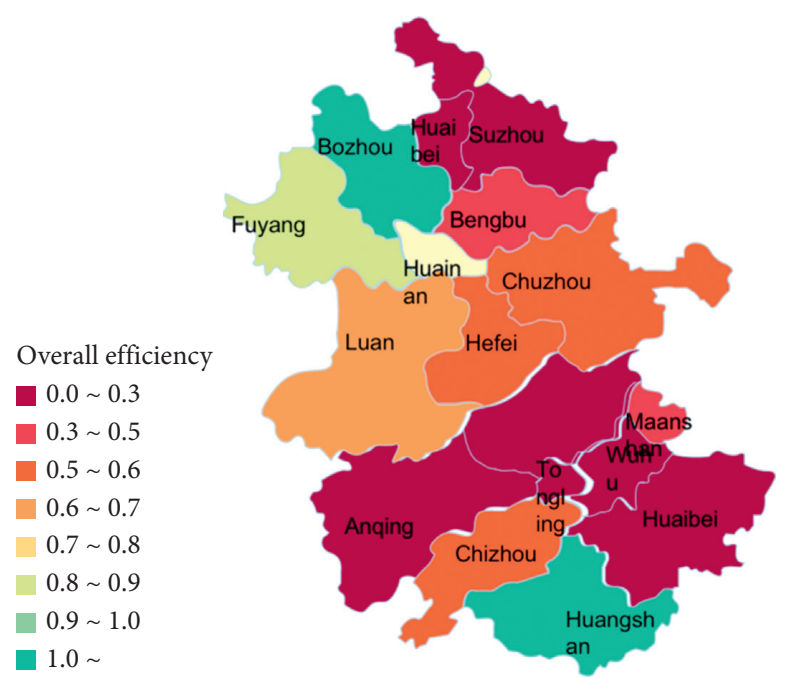

Figure 3: Overall efficiency 2011.

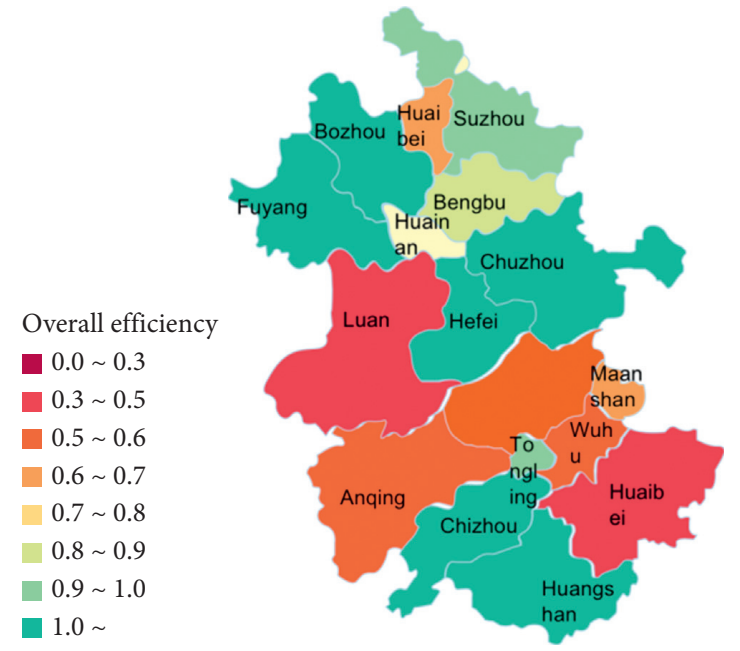

FIgURE 4: Overall efficiency 2015.

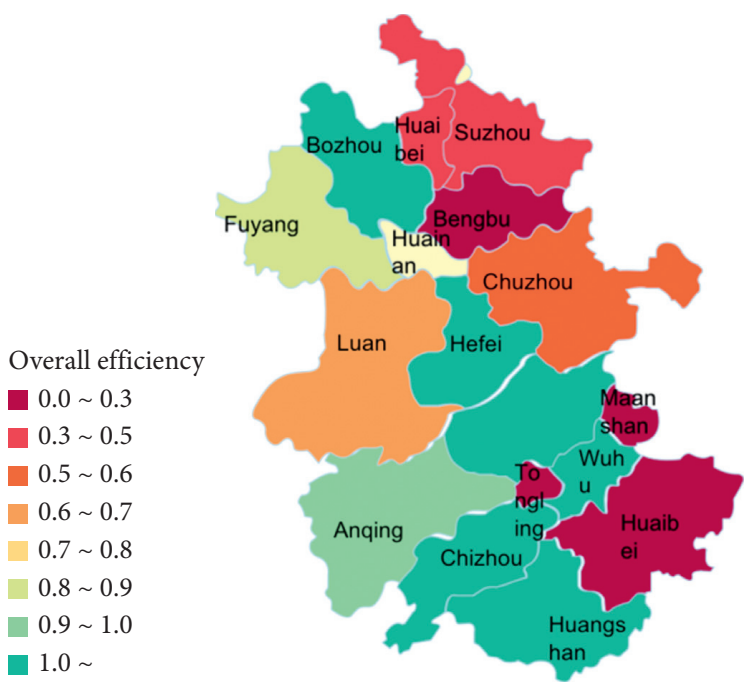

Figure 5: Overall efficiency 2019. 
means that the level of technical efficiency is higher and the use of resources is more reasonable. Table 3 shows the results of the technical efficiency from 2011 to 2019.

The average value of the pure technical efficiency of inbound tourism in Anhui cities is 0.71, which indicates that the cities in Anhui province have a high level of input and use of technical factors in inbound tourism. The pure technical efficiency of Hefei, Chizhou, and Huangshan is always 1, indicating that these three cities have the highest level of input, development, and allocation of inbound tourism resources and the highest level of use of technical factors. The efficiency values of Chuzhou and Xuancheng cities have been lower than the average of pure technical efficiency, which is mainly influenced by the overall efficiency, which requires that in the process of urban economic development, we should also pay attention to the input and use of technology level and rational allocation of resources, not just blindly seeking development (Figures 6-8).

3.3. Scale Efficiency. Scale efficiency is used to calculate the distance between the production frontier between variable and constant returns and scale to indicate the degree to which economies of scale are effective when the decision unit is located at a certain point. In the tourism industry, it is used to calculate whether the increase in tourism factor inputs in a city brings about a corresponding increase in tourism efficiency, whether it meets the needs of the city's tourism development, and whether it forms certain scale benefits. When the obtained value is 1 , it means that the calculation of the decision unit is effective; when the value is less than 1 , it means that the decision unit is invalid, and further analysis of the decision unit is needed. Table 4 shows the scale efficiency results of inbound tourism in Anhui cities from 2011 to 2019 .

The average value of scale efficiency for each city in 2011-2019 is above 0.6, which means that the average efficiency reaches more than $60 \%$ of the optimal level, where the highest value of scale efficiency is in 2016, with the average value of scale reaching 0.93 , indicating that the scale of investment in inbound tourism is more appropriate for each city in 2016, and the scale of investment in tourism resources also allows inbound tourism to reach the maximum The cities' investment in tourism factors can meet the development of the city's inbound tourism industry. This is mainly due to the fact that 2016 was the beginning of the 13th Five-Year Plan, with significant achievements in the development of cultural industries and tourism, increased support from the state for tourism development, and the development of inbound tourism in all cities under the "One Belt, One Road" initiative. The year with the lowest average value of scale efficiency was 2011, mainly because 2011 was the beginning of the 12th Five-Year Plan, the country was in a period of transition in the face of a complex and changing situation at home and abroad, and the development of inbound tourism was in a difficult situation (Figures 9-11).

3.4. Total Factor Productivity. Total factor productivity of tourism is an important basis for measuring whether tourism resources are reasonably allocated and the level of tourism economic development. This study obtained the total factor productivity of 16 cities in Anhui province from 2011 to 2019 by the Malmquist index model, as shown in Table 5.

The average value of total factor productivity for the 16 cities is 1.05 . The overall productivity index is increasing, and the total factor productivity of each city is improving. Combining the technical efficiency change index and the technological progress change index, it is clear that technological progress is an important driver for the growth of inbound tourism efficiency in Anhui province, but it is also necessary to further improve the growth of scale efficiency. From the table, it can be seen that the technological progress of all 16 cities is growing, and the technological progress indexes of Hefei, Huaibei, Fuyang, Maanshan, and Wuhu are higher than the provincial average. The technical efficiency of Chizhou and Huangshan, which are the most mature cities in Anhui province in terms of tourism development, and the competition from Hefei and other cities make it difficult to make a significant breakthrough in technical efficiency. The technical efficiency of Huabei, Suizhou, Bengbu, Maanshan, and Tongling is slow, mainly because they are resource-based cities that lack certain tourism resources to attract more inbound tourists and because they do not pay enough attention to technical investment, which makes the development of inbound tourism industry slow. Finally, the geographic heat map (Figures 3-11) visualizes the trends of overall efficiency, pure technical efficiency, and scale efficiency in Anhui province.

3.5. Analysis of Influencing Factors. Before the empirical analysis of the selected indicators, the independent variables were analyzed for multiple cointegrations, and the variance inflation factors of the seven indicators in the cointegration results were all much less than the critical value of 10 , indicating that there were no multiple cointegrations in the independent variables. Regression analysis was conducted using SPSS 25.0 software, and the results showed that different independent variable factors had different levels of significance on the development efficiency of inbound tourism (Table 6).

The level of economic development, tourism resource endowment, transportation accessibility, and talent scale all have a significant positive impact on the development efficiency of inbound tourism and are the main influencing factors to enhance the efficiency of inbound tourism. The higher the level of economic development means the better the infrastructure and service facilities of the destination and, accordingly, the stronger the ability to accommodate international tourists. Tourism resource endowment is the basis for determining the development of inbound tourism. The tourism efficiency of inbound development in Huangshan and Chizhou of Anhui province has been maintained at a high level, fundamentally because the tourism resource endowment of these two cities is far ahead in the province. Accessibility determines the accessibility of the destination, and especially for international tourists, 
TABLE 3: Results of technical efficiency on inbound tourism.

\begin{tabular}{|c|c|c|c|c|c|c|c|c|c|}
\hline & 2011 & 2012 & 2013 & 2014 & 2015 & 2016 & 2017 & 2018 & 2019 \\
\hline Hefei & 1.00 & 1.00 & 1.00 & 1.00 & 1.00 & 1.00 & 1.00 & 1.00 & 1.00 \\
\hline Huaibei & 0.41 & 1.00 & 0.94 & 1.00 & 1.00 & 1.00 & 0.47 & 1.00 & 0.98 \\
\hline Bozhou & 1.00 & 0.18 & 0.65 & 0.76 & 1.00 & 0.80 & 0.85 & 1.00 & 1.00 \\
\hline Suzhou & 0.88 & 0.41 & 1.00 & 0.94 & 1.00 & 0.71 & 1.00 & 0.53 & 0.66 \\
\hline Bengbu & 0.30 & 0.82 & 0.25 & 0.55 & 0.90 & 0.88 & 0.24 & 1.00 & 0.20 \\
\hline Fuyang & 0.80 & 1.00 & 0.56 & 1.00 & 1.00 & 1.00 & 1.00 & 0.50 & 0.80 \\
\hline Huainan & 0.50 & 0.52 & 0.44 & 0.83 & 0.94 & 1.00 & 0.90 & 0.62 & 1.00 \\
\hline Chuzhou & 0.10 & 0.38 & 0.26 & 0.36 & 1.00 & 0.54 & 0.53 & 1.00 & 0.66 \\
\hline Luan & 0.50 & 0.65 & 0.57 & 0.60 & 0.66 & 0.77 & 0.89 & 1.00 & 1.00 \\
\hline Maanshan & 0.56 & 1.00 & 1.00 & 1.00 & 0.69 & 1.00 & 0.18 & 0.21 & 0.22 \\
\hline Wuhu & 0.18 & 0.69 & 0.61 & 0.95 & 0.52 & 0.89 & 0.50 & 1.00 & 1.00 \\
\hline Xuancheng & 0.60 & 0.25 & 0.19 & 0.41 & 0.45 & 0.46 & 0.15 & 0.18 & 0.22 \\
\hline Tongling & 1.00 & 1.00 & 1.00 & 1.00 & 1.00 & 0.33 & 0.14 & 0.17 & 0.39 \\
\hline Chizhou & 1.00 & 1.00 & 1.00 & 1.00 & 1.00 & 1.00 & 1.00 & 1.00 & 1.00 \\
\hline Anqing & 0.11 & 0.71 & 0.54 & 1.00 & 0.82 & 1.00 & 0.25 & 0.56 & 1.00 \\
\hline Huangshan & 1.00 & 1.00 & 1.00 & 1.00 & 1.00 & 1.00 & 1.00 & 1.00 & 1.00 \\
\hline Mean & 0.39 & 0.77 & 0.65 & 0.85 & 0.87 & 0.84 & 0.49 & 0.85 & 0.72 \\
\hline
\end{tabular}

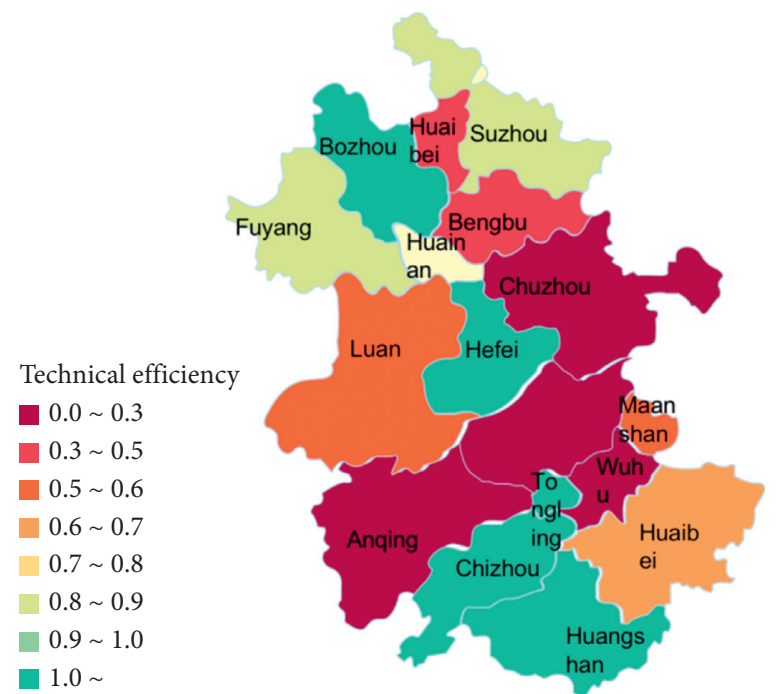

Figure 6: Technical efficiency 2011.

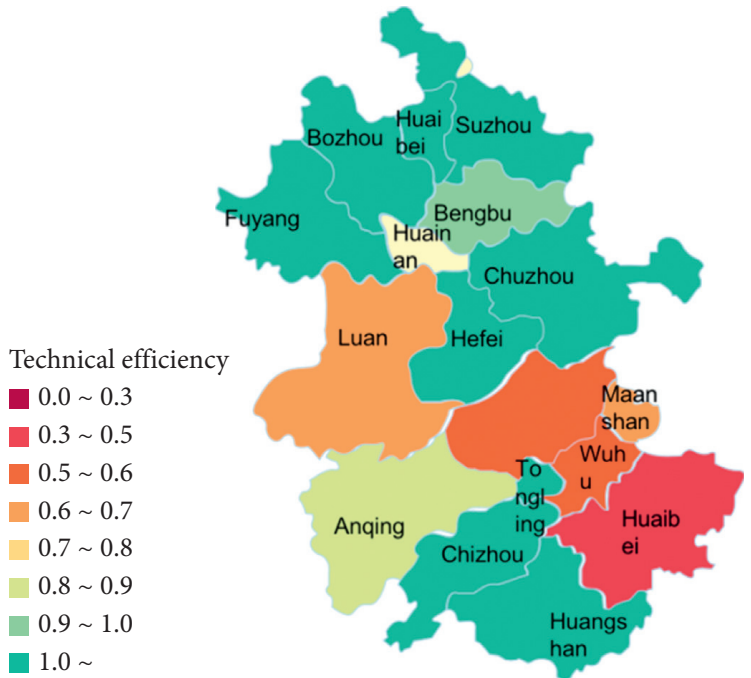

Figure 7: Technical efficiency 2015. 


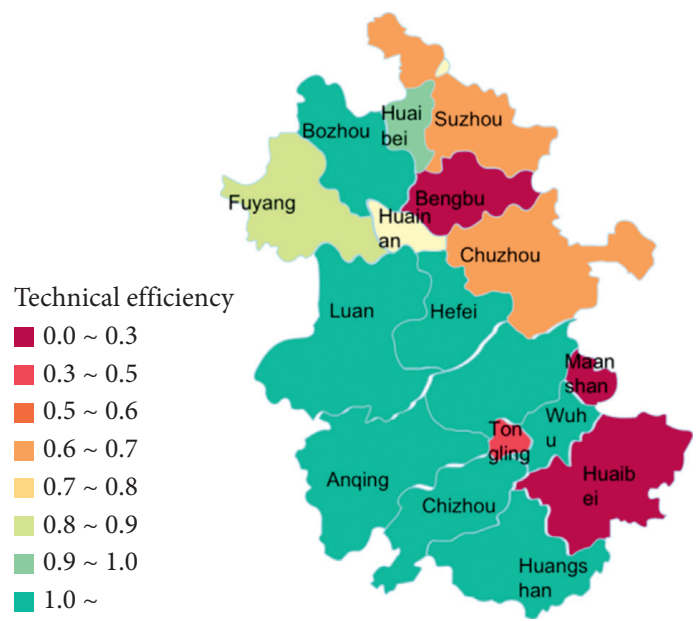

Figure 8: Technical efficiency 2019.

TABLE 4: Results of scale efficiency on inbound tourism.

\begin{tabular}{llllllllll}
\hline & 2011 & 2012 & 2013 & 2014 & 2015 & 2016 & 2017 & 2018 & 2019 \\
\hline Hefei & 0.84 & 0.85 & 0.96 & 0.86 & 0.90 & 1.00 & 1.00 & 1.00 & 1.00 \\
Huaibei & 0.25 & 0.30 & 0.51 & 0.36 & 0.51 & 0.63 & 0.53 & 0.12 & 0.45 \\
Bozhou & 1.00 & 0.80 & 0.76 & 0.84 & 0.84 & 1.00 & 0.82 & 0.80 & 1.00 \\
Suzhou & 0.54 & 0.33 & 0.49 & 0.37 & 0.68 & 0.98 & 0.81 & 0.80 & 1.00 \\
Bengbu & 0.91 & 0.90 & 0.90 & 0.94 & 0.91 & 0.95 & 0.88 & 0.74 & 0.96 \\
Fuyang & 0.36 & 0.50 & 0.63 & 0.72 & 0.80 & 1.00 & 1.00 & 0.72 & 0.53 \\
Huainan & 0.75 & 0.74 & 0.72 & 0.84 & 0.80 & 0.99 & 1.00 & 0.91 \\
Chuzhou & 0.90 & 0.90 & 0.99 & 1.00 & 0.95 & 1.00 & 0.93 & 0.66 \\
Luan & 0.98 & 1.00 & 0.98 & 0.97 & 0.98 & 0.74 & 1.00 & 0.94 \\
Maanshan & 0.70 & 1.00 & 1.00 & 1.00 & 0.91 & 0.93 & 1.00 & 0.97 \\
Wuhu & 0.96 & 0.90 & 0.91 & 0.73 & 0.99 & 0.98 & 0.99 & 0.90 & 1.00 \\
Xuancheng & 0.85 & 0.90 & 0.97 & 0.99 & 0.92 & 0.99 & 1.00 & 0.94 \\
Tongling & 0.55 & 0.20 & 0.15 & 0.18 & 0.48 & 0.98 & 0.75 & 0.68 \\
Chizhou & 0.81 & 1.00 & 1.00 & 1.00 & 1.00 & 1.00 & 1.00 & 1.00 & 0.96 \\
Anqing & 0.90 & 1.00 & 1.00 & 0.92 & 1.00 & 0.68 & 0.94 & 0.78 \\
Huangshan & 1.00 & 1.00 & 1.00 & 1.00 & 1.00 & 1.00 & 1.00 & 1.00 \\
Mean & 0.64 & 0.77 & 0.79 & 0.77 & 0.85 & 0.93 & 0.91 & 0.75 \\
\hline
\end{tabular}

Scale efficienc
$0.0 \sim 0.3$
$0.3 \sim 0.5$
$0.5 \sim 0.6$
$0.6 \sim 0.7$
$0.7 \sim 0.8$
$0.8 \sim 0.9$
$0.9 \sim 1.0$
$1.0 \sim$

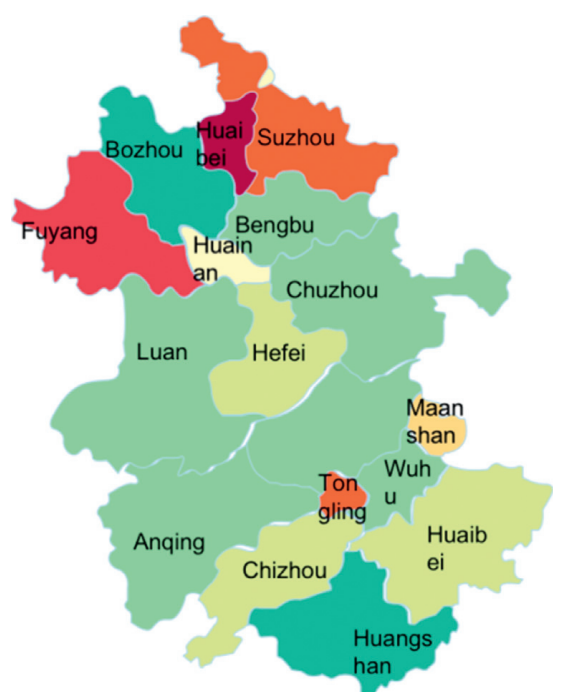

Figure 9: Scale efficiency 2011. 


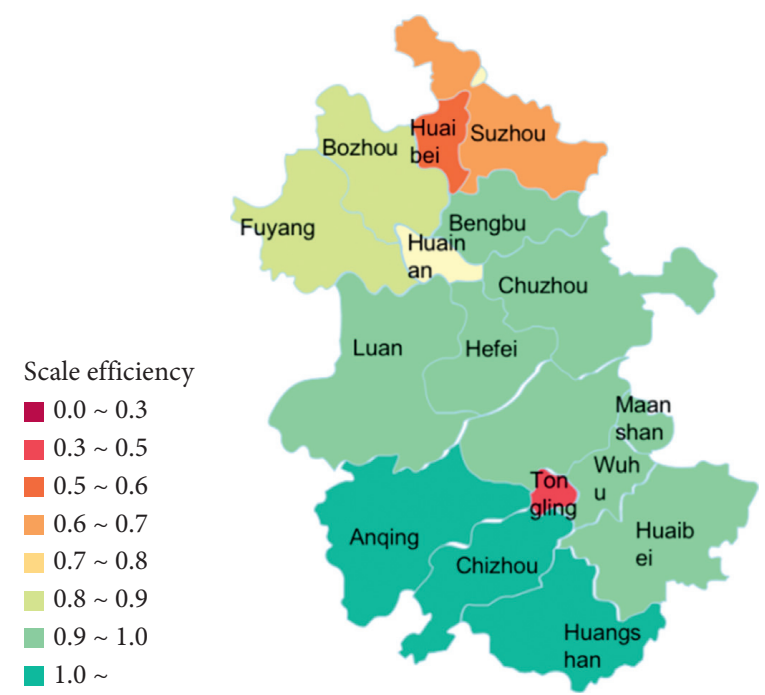

Figure 10: Scale efficiency 2015.

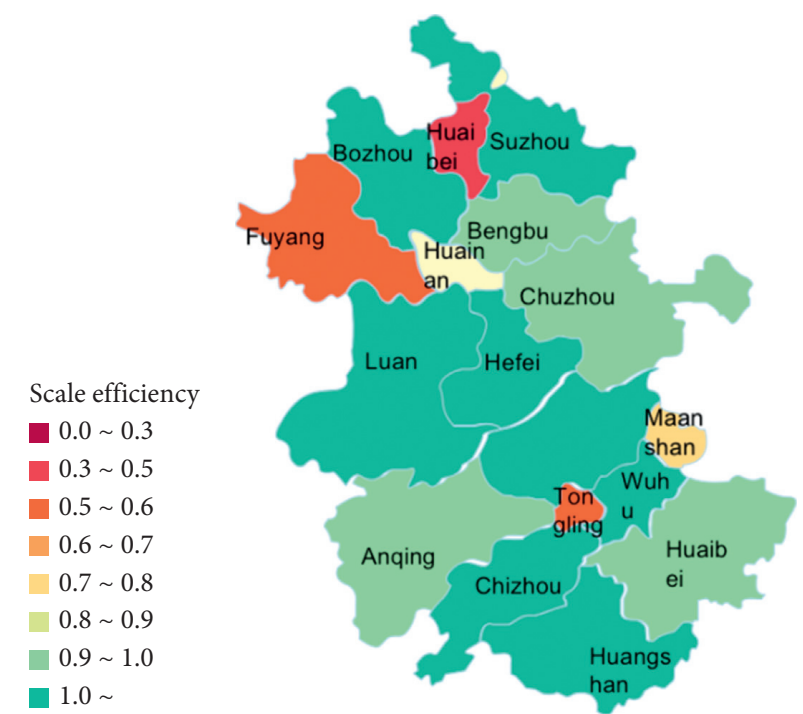

Figure 11: Scale efficiency 2019.

Table 5: The Malmquist index and its decomposition of the inbound tourism efficiency in Anhui province from 2011 to 2019.

\begin{tabular}{|c|c|c|c|c|c|}
\hline & EFFCH & TECH & $\mathrm{PECH}$ & SECH & TFP \\
\hline Hefei & 1.27 & 1.05 & 1.10 & 1.97 & 1.84 \\
\hline Huaibei & 1.05 & 0.94 & 1.00 & 1.15 & 1.08 \\
\hline Bozhou & 1.00 & 0.81 & 1.00 & 1.00 & 0.81 \\
\hline Suzhou & 1.04 & 0.93 & 1.19 & 1.04 & 1.16 \\
\hline Bengbu & 1.03 & 0.93 & 0.92 & 1.11 & 0.95 \\
\hline Fuyang & 1.41 & 1.02 & 1.05 & 1.09 & 1.20 \\
\hline Huainan & 1.36 & 0.91 & 1.28 & 1.07 & 1.24 \\
\hline Chuzhou & 1.13 & 0.92 & 1.10 & 1.03 & 1.04 \\
\hline Luan & 1.34 & 0.89 & 1.32 & 1.01 & 1.18 \\
\hline Maanshan & 1.02 & 1.02 & 1.01 & 1.01 & 1.05 \\
\hline Wuhu & 1.22 & 0.96 & 1.21 & 1.01 & 1.17 \\
\hline Xuancheng & 1.12 & 0.92 & 1.18 & 1.12 & 1.12 \\
\hline Tongling & 0.93 & 0.91 & 0.89 & 1.12 & 1.12 \\
\hline Chizhou & 1.04 & 1.01 & 1.02 & 1.02 & 1.04 \\
\hline Anqing & 1.32 & 0.84 & 1.30 & 1.01 & 1.11 \\
\hline Huangshan & 1.00 & 0.91 & 1.00 & 1.00 & 0.91 \\
\hline Mean & 1.13 & 0.94 & 1.09 & 1.04 & 1.07 \\
\hline
\end{tabular}


TABLE 6: Regression results of factors influencing the overall efficiency of inbound tourism.

\begin{tabular}{|c|c|c|c|c|c|c|}
\hline Factors & Non-SC & SE & SC & $\mathrm{T}$ & $p$ & VIF \\
\hline Constant & 0.222 & 0.234 & - & 0.588 & 0.563 & 7.124 \\
\hline Eco & 0.241 & 0.134 & $0.468^{* * *}$ & 3.624 & 0.002 & 2.314 \\
\hline Str & 0.412 & 0.136 & 0.315 & 1.114 & 0.444 & 5.127 \\
\hline Gov & 0.513 & 0.224 & 0.063 & 0.989 & 0.342 & 1.989 \\
\hline Tre & 0.574 & 0.167 & $0.863^{* * *}$ & 5.241 & 0.000 & 1.299 \\
\hline Tra & 0.442 & 0.189 & $0.724^{* * *}$ & 4.224 & 0.000 & 1.764 \\
\hline Hrs & 0.612 & 0.229 & $0.456^{* * *}$ & 2.929 & 0.005 & 2.937 \\
\hline Tei & 0.609 & 0.314 & 0.134 & 1.347 & 0.127 & $3 / 418$ \\
\hline
\end{tabular}

Note. $\mathrm{SC}=$ standardized coefficient and $\mathrm{SE}=$ standardized error.

accessibility is the basic factor to satisfy their access to the destination. The scale of human resources also has a significant impact on the efficiency of inbound tourism development, suggesting that the size of tourism talent largely influences the high quality of tourism development.

Surprisingly, there is no significant effect of industrial structure, government intervention, and technological innovation on the efficiency of inbound tourism development. For the industrial structure, it indicates that the role of inbound tourism in the overall tourism development in Anhui province is still low and the ability to change the industrial structure is weak. The nonsignificance for government intervention suggests that inbound tourism is tourism attraction driven and the role of government policy support is low when the core attractiveness of the destination is insufficient. Finally, the insignificance of technological innovation may be explained by the fact that Anhui province is still a natural tourism resource-driven destination and the role of technological innovation in the high-quality transformation of tourism needs to be strengthened in the future.

\section{Conclusions}

Based on 16 cities in Anhui province, the analysis of the DEA model and Malmquist index model from 2011 to 2019 reveals the regional tourism impact. The results show that the average value of the overall efficiency of inbound tourism from 2011 to 2019 is in the range of $0.6-0.7$, the average value of pure technical efficiency is in the range of $0.7-0.8$, and the average value of scale efficiency is in the range of 0.6-0.7. This indicates that the development of inbound tourism in Anhui cities is relatively stable, and the overall efficiency and scale efficiency of inbound tourism are gradually maturing, and the level of investment and use of technology are increasing. The overall development of inbound tourism in Anhui province is relatively stable, and the whole tourism industry is developing with good momentum. The use of pure technical efficiency is also improving, indicating that Anhui province, as a large tourism province, has a certain industrial scale for the development of inbound tourism, and the next step is only to focus on improving the overall efficiency to achieve high speed and quality of inbound tourism and to highlight the role of new technologies, resources, and methods to promote the development of inbound tourism. The average value of total factor productivity of inbound tourism in Anhui province reaches 1.05 , and the overall total factor development is in the process of continuous development, with Hefei, Fuyang, and Wuhu as the innovative development cities and Lu'an as the late-developing tourism city that most rapidly develops. The total factor productivity of inbound tourism has not changed much. For resource-based cities such as Huabei, Huainan, and Maanshan, which lack certain tourism resources, the development of inbound tourism is still in the process of continuous exploration, and the total factor productivity growth rate is slow. We also found that inbound tourism efficiency in Anhui province is influenced by the level of economic development, tourism resource endowment, accessibility, and the scale of human resources but not by industrial structure, government intervention, or technological innovation, suggesting that inbound tourism is essentially natural resource, infrastructure, and service facility driven. This study is important for guiding the high-quality transformation of regional inbound tourism development.

Practically, this study provides additional policy options for a comprehensive understanding of the economic impact of tourism and should focus more on increasing tourism efficiency rather than the constant investment of resources. Theoretically, this study finds that the mechanism of action of tourism's impact on the region is through the expansion of real demand in the local market, which in turn reduces production costs and promotes the formation of economies of scale, thus increasing scale efficiency, while having a limited effect on the improvement of technical efficiency. It can also be shown that the relationship between tourism and regional economic development is dialectical and complex and that it is difficult to establish causality at the empirical level.

The study has the following shortcomings. First, this study only chose inbound tourism to characterize the regional tourism economic effect, although inbound tourism is an important dimension to measure the economic situation of tourism, it is still far from the actual meaning of regional tourism impact, and more comprehensive evaluation dimensions need to be further considered in the future. Second, this study only chose Anhui province as a case site, which can be used as a case in China in the future to more comprehensively reveal the economic impact of tourism. 


\section{Data Availability}

The data used to support the findings of this study are available from the corresponding author upon request.

\section{Conflicts of Interest}

The authors declare that they have no known competing financial interests or personal relationships that could have appeared to influence the work reported in this paper.

\section{Acknowledgments}

This work did not receive any fundings.

\section{References}

[1] X. A. Wang, G. N. Sun, and M. Y. Gun, "An analysis on the changes of quantity and quality of inbound tourism flow to Anhui province," East China Economic Management, vol. 30, no. 3, pp. 27-33, 2016.

[2] J. Liu and P. Nijkamp, "Inbound tourism as a driving force for regional innovation: a spatial impact study on China," Journal of Travel Research, vol. 58, no. 4, pp. 494-607, 2019.

[3] Y. Y. Sun, M. A. Cadarso, and S. Driml, "Tourism carbon footprint inventories: a review of the environmentally extended input-output approach," Annals of Tourism Research, vol. 82, Article ID 102928, 2020.

[4] T. Ghalia and J. Fidrmuc, "The curse of tourism?" Journal of Hospitality \& Tourism Research, vol. 42, no. 6, pp. 979-996, 2018.

[5] R. C. Morey and D. A. Dittman, "Evalatn a hotel GM's performance," Cornell Hotel and Restaurant Administration Quarterly, vol. 36, no. 5, pp. 30-35, 1995.

[6] M. Arbelo-Pérez, A. Arbelo, and P. Pérez-Gómez, "Technological heterogeneity and hotel efficiency: a bayesian approach," Cornell Hospitality Quarterly, vol. 61, no. 2, pp. 170-182, 2020.

[7] X. Xu and C. G.-Q. Chi, "Examining operating efficiency of U.S. Hotels: a window data envelopment analysis approach," Journal of Hospitality Marketing \& Management, vol. 26, no. 7, pp. 770-784, 2017.

[8] L. F. Mendieta-Peñalver, J. F. Perles-Ribes, A. B. RamonRodriguez, and M. J. Such-Devesa, "Is hotel efficiency necessary for tourism destination competitiveness? An integrated approach," Tourism Economics, vol. 24, no. 1, pp. 3-26, 2018.

[9] R. Lado-Sestayo and Á. S. Fernández-Castro, "The impact of tourist destination on hotel efficiency: a data envelopment analysis approach," European Journal of Operational Research, vol. 272, no. 2, pp. 674-686, 2019.

[10] S. Niavis and D. Tsiotas, "Assessing the tourism performance of the Mediterranean coastal destinations: a combined efficiency and effectiveness approach," Journal of Destination Marketing \& Management, vol. 14, Article ID 100379, 2019.

[11] Y. Liu, T. Xiao, Z. P. Fan, and X. Zhao, "Pricing, environmental governance efficiency, and channel coordination in a socially responsible tourism supply chain," International Transactions in Operational Research, vol. 26, no. 3, pp. 1025-1051, 2019.

[12] S. Lidelöw, T. Örn, A. Luciani, and A. Rizzo, "Energy-efficiency measures for heritage buildings: a literature review," Sustainable Cities and Society, vol. 45, pp. 231-242, 2019.

[13] D. Dragan, A. Keshavarzsaleh, B. Jereb, and D. Topolšek, "Integration with transport suppliers and efficiency of travel agencies," International Journal of Value Chain Management, vol. 9, no. 2, pp. 122-148, 2018.

[14] H. Huang, Y. Liu, and D. Lu, "Proposing a model for evaluating market efficiency of OTAs: theoretical approach," Tourism Economics, vol. 26, no. 6, pp. 958-975, 2020.

[15] X. Li, X. Zhao, and D. Bai, "Marine transport efficiency evaluation of cross-border logistics based on AHP-TOPSIS method," Journal of Coastal Research, vol. 110, no. SI, pp. 95-99, 2020.

[16] H. Li, G. Gozgor, C. K. M. Lau, and S. R. Paramati, "Does tourism investment improve the energy efficiency in transportation and residential sectors? Evidence from the OECD economies," Environmental Science and Pollution Research, vol. 26, no. 18, pp. 18834-18845, 2019.

[17] R. Tang, "Trade facilitation promoted the inbound tourism efficiency in Japan," Tourism Management Perspectives, vol. 38, Article ID 100805, 2021.

[18] H.-S. Chen, B.-K. Tsai, G.-B. Liou, and C.-M. Hsieh, "Efficiency assessment of inbound tourist service using data envelopment analysis," Sustainability, vol. 10, no. 6, pp. 1866-1894, 2018.

[19] N. Mou, R. Yuan, T. Yang, H. Zhang, J. J. Tang, and T. Makkonen, "Exploring spatio-temporal changes of city inbound tourism flow: the case of Shanghai, China," Tourism Management, vol. 76, Article ID 103955, 2020.

[20] Y. Han, R. Zhou, Z. Geng, J. Bai, B. Ma, and J. Fan, “A novel data envelopment analysis cross-model integrating interpretative structural model and analytic hierarchy process for energy efficiency evaluation and optimization modeling: application to ethylene industries," Journal of Cleaner Production, vol. 246, Article ID 118965, 2020.

[21] A. Corne, "Benchmarking and tourism efficiency in France," Tourism Management, vol. 51, pp. 91-95, 2015.

[22] Q. Zhu, X. Li, F. Li, and D. Zhou, "The potential for energy saving and carbon emission reduction in China's regional industrial sectors," The Science of the Total Environment, vol. 716, Article ID 135009, 2020.

[23] P. Zhang, L. X. Li, and Y. Q. Zeng, "Research on the evaluation of technological innovation efficiency in Guangdong-Hong Kong-Macao Greater Bay Area based on DEA-Malmquist index," Industrial Technology Economy, vol. 40, no. 2, pp. 12-17, 2021.

[24] L. Yang, J.-J. Chen, P.-F. Shi, and G.-Q. Huang, "The evaluation of red tourism development efficiency and its influencing factors: a case study of the red tourism region in Northern and Western Guizhou," Journal of Natural Resources, vol. 36, no. 11, pp. 2763-2777, 2021. 